\title{
A hospital-based study on complementary and alternative medicine use among diabetes patients in Rajshahi, Bangladesh
}

Md. Abdur Rafi ${ }^{1}$, Dewan Tasnia Azad ${ }^{2}$, Mridula Bhattacharjee ${ }^{3}$, Nikita Rahman ${ }^{1}$, Kazi Abdul Mubin ${ }^{4}$, Md. Ajijur Rahman ${ }^{4}$ and Md. Golam Hossain ${ }^{5^{*}}$

\begin{abstract}
Background: The use of complementary and alternative medicine (CAM) among type 2 diabetes mellitus (T2DM) patients is increasing worldwide. It can affect optimum glycemic management. This study was to determine the rate and influencing factors of CAM use among diabetes patients as well as their effect on glycemic control.

Methods: This cross-sectional study was conducted among T2DM patients attending the outpatient department of Rajshahi Medical College Hospital. It is a tertiary hospital in the northern part of Bangladesh. A face-to-face interview with a pretested structured questionnaire was used for data collection. Chi-square $\left(x^{2}\right)$ test and multivariate logistic regression model were used in this study for data analysis.

Results: Out of 244 T2DM patients, 86 (35.2\%) used CAM. Multivariate logistic regression model showed that lower family income group ( $A O R=8.7,95 \% \mathrm{Cl}: 2.15-35.22$, $p$-value 0.002 ), having no institutional education ( $A O R=3.4,95 \%$ Cl: 1.17-9.87, $p$-value 0.025) and having diabetes for more than five years ( $A O R=2.821,95 \% \mathrm{Cl}$ : 1.34-5.94, $\mathrm{p}$-value 0.006) were the most influential predictors of CAM use. The most commonly used CAMs were herbal products (67.4\%) and homeopathic medicine (37.2\%). Most of the CAM users (72\%) were influenced by friends, neighbors, and family members. The most common reasons behind CAM use were reported to be the belief that CAM helped control diabetes better (44.2\%) and easy availability and lower cost (27.9\%). More than half of the users reported the efficacy of CAM as 'nothing significant', while others reported as somewhat good. 14\% of CAM users experienced side-effects, especially gastrointestinal upset. It was observed that using CAM was associated with poor glycemic control $(A O R=$ 2.25, 95\% Cl: 1.14-4.44, p-value 0.018).

Conclusion: Our study demonstrated that some modifiable factors are associated with the use of CAM, and it cannot maintain good glycemic control. So, patients should be made aware of the ineffectiveness and bad effects of CAM by enhancing educational and poverty-alleviating programs.
\end{abstract}

Keywords: Complementary and alternative medicine, Type 2 diabetes mellitus, Hospital-based, Glycemic control, Bangladesh

\footnotetext{
* Correspondence: hossain95@yahoo.com

${ }^{5}$ Department of Statistics, University of Rajshahi, 6205, Rajshahi, Bangladesh

Full list of author information is available at the end of the article
}

(c) The Author(s). 2020 Open Access This article is licensed under a Creative Commons Attribution 4.0 International License, which permits use, sharing, adaptation, distribution and reproduction in any medium or format, as long as you give appropriate credit to the original author(s) and the source, provide a link to the Creative Commons licence, and indicate if changes were made. The images or other third party material in this article are included in the article's Creative Commons licence, unless indicated otherwise in a credit line to the material. If material is not included in the article's Creative Commons licence and your intended use is not permitted by statutory regulation or exceeds the permitted use, you will need to obtain permission directly from the copyright holder. To view a copy of this licence, visit http://creativecommons.org/licenses/by/4.0/ The Creative Commons Public Domain Dedication waiver (http://creativecommons.org/publicdomain/zero/1.0/) applies to the data made available in this article, unless otherwise stated in a credit line to the data. 


\section{Background}

Type 2 diabetes mellitus (T2DM) has become a major public health concern worldwide. Over the last two decades, diabetes has substantially increased in terms of an absolute number of years of life lost and years lived with disability [1], and it affects more than 382 million people globally [2]. A large portion of diabetes patients lives in South East Asia [3]. Bangladesh, a developing country of this region, has more than 8.4 million diabetes patients, which constitutes almost $8 \%$ of the total adult population of the country [3]. The health system of Bangladesh is inadequate to provide the essential services for this large number of patients.

Recent advances in diabetic care have made good glycemic control possible, but yet modern medications and essential lifestyle modifications cannot cure diabetes rather patients have to continue lifelong therapy. These issues are making patients interested in various complementary and alternative medicines (CAM) [4], which refers to 'a group of diverse medical and health care systems, practices, and products that are not presently considered to be part of conventional medicine' [4, 5]. The use of such alternative therapies is increasing in different countries [4, 6-8]. Patients' demographic characteristics, experience, health beliefs and attitudes, and behavior toward disease and therapies can influence their practice of using CAM therapy [9]. Different categories of CAM were reported to be used by diabetes patients including biological therapies like an herbal and dietary supplement, alternative medical systems like acupuncture or ayurveda, energy therapies like reiki, manipulative and body-based systems like chiropractic or massage, and mind-body interventions like tai-chi or yoga $[4,10]$.

The effect of CAM use on glycemic control is still controversial. A few evidences are showing that the use of CAM, especially different herbs and supplements can be beneficial for diabetes management and self-care [4, 11]. However, these herbal therapies may have sideeffects if not used correctly [12]. Moreover, increasing dependence on alternative therapy may have a negative impact on glycemic control and patients' quality of life [6]. As diabetes is a self-managed disease, a patientcentered approach for diabetes management is more effective for therapeutic compliance [13]. Their attitude and practice of using alternative therapy may influence medication compliance and glycemic control. Potential physiological impacts like medication interaction with CAM therapies and their side-effects should also be taken into account [11]. Understanding the prevalence and pattern of use of different complementary and alternative therapies and beliefs and attitudes of patients toward these is important for effective diabetes management.
CAM is widely used in Bangladesh both for the prevention and treatment of various diseases. It is estimated that more than two-thirds of the population are still using alternative traditional medicine in this country [14]. Most commonly practiced CAMs in Bangladesh are herbal, homeopathy, traditional, and religious methods. Sometimes these alternative and traditional methods of treatment reach beyond the boundary of health to the wider environment of society, religion, and culture of the community. Despite the wide acceptance of CAM along with modern medicine, there is still no specific data on the pattern of using these therapies among T2DM patients is available in the context of Bangladesh.

The present study was to determine the rate of CAM use, its associated factors, and the effect on glycemic control among diabetic patients of the northern part of Bangladesh.

\section{Methods}

\section{Study setting and participants}

This cross-sectional study was conducted during November and December 2019 in the outpatient department of Rajshahi Medical College Hospital (RMCH), a tertiary care teaching hospital in the Northern part of Bangladesh, with the well-established outpatient facility. According to hospital records, more than 1000 patients take medical services from the outpatient department of $\mathrm{RMCH}$ daily. It is the main treatment facility for the people living in different districts of the northern part of Bangladesh (Rajshahi, Rangpur and Khulna division).

\section{Sample size determination and sampling}

The following formula was used to calculate the sample size for the current study:

$$
n=\frac{z^{2} p q}{d^{2}}
$$

where $\mathrm{n}=$ number of sample; $\mathrm{z}=1.96$ for $95 \%$ confidence level $(\mathrm{CI}), \mathrm{p}=$ the proportion of prevalence and $\mathrm{d}=$ precision of the prevalence estimate. There was no previous evidence of the prevalence of CAM use among Bangladeshi T2DM patients. However, a Malaysian study reported that the prevalence of CAM use among diabetes patients was $62.5 \%$ [8]. A total number of 240 diabetic patients were used as sample for their study and they got the prevalence of CAM use was $62.5 \%$. We did not follow their sample size, we just took the prevalence of CAM for calculating our sample size. We considered $p=62.5 \%=0.625$, so $\mathrm{q}=1-p=1-0.625=0.375$. Taking this into account assuming $10 \%$ precision of the prevalence estimate $(d=0.0625)$ and $95 \% \mathrm{CI}, 231$ samples were sufficient for this study. Assuming a 10\% 
nonresponsive rate total of 260 diabetic patients were considered.

Patients were selected using a purposive sampling method. Patients aged more than 18 years and diagnosed as T2DM for at least one year were included in this study. Patients diagnosed as other types of diabetes, diagnosed for less than one year, and the patients with complications who needed hospitalization were excluded. After eliminating incomplete responses data from 244 participants were finally analyzed.

\section{Data collection instrument and procedure}

Data were collected by face-to-face interviews using a structured questionnaire (Additional file: Questionnaire). A written consent was taken from each participant. The questionnaire included patients' socio-demographic data, diabetes-related information, types of CAM used, and source of motivation for using CAM. The attitudes, beliefs, and perceptions toward CAM were also explored. Results of glycosylated hemoglobin (HbA1c) test from the current visit, when the interview was conducted, were collected from the patients' medical records. A pilot survey involving 20 patients was conducted to pretest the questionnaire and estimate the likely response rate. The interview was carried out by three trained medical students.

\section{Outcome variable}

The use of CAM was the outcome variable of this study and the sample was classified according to CAM usage such as (i) CAM user (code, 1) and (ii) CAM non-user (code, 0). Another outcome variable in this study was glycemic control; the sample was divided into two classes; (i) poor control (code, 0) and (ii) good control (code, 1). Cut off value of poor glycemic control was set as HbA1c $\geq 7 \%$ and for good glycemic control, it was $<7 \%$. These cut off values were taken from previous evidence of glycemic control among Bangladeshi diabetic patients $[15,16]$.

\section{Independent variables}

Some socio-demographic and diabetes-related factors were considered as independent variables in this study. Most of the independent variables were selected based on previous studies $[7,8]$. The names of variables with group and code are given in Table 1.

\section{Statistical analysis}

Statistical analyses were carried out using SPSS (IBM version 22.0). The qualitative variables were described in terms of frequencies and percentages, and continuous variables in terms of means and standard deviations. The association between socio-demographic or diabetesrelated factors and the use of CAM was determined by using Chi-square $\left(x^{2}\right)$ test. Multivariate logistic regression was used to identify the most influential predictors of CAM usage. Multivariate logistic regression adjusted for socio-demographic and diabetes-related factors were used to find out the effect of CAM usage on glycemic control.

Table 1 List of independent variables with group and code

\begin{tabular}{|c|c|c|c|c|c|}
\hline Variable & Group & Code & Variable & Group & Code \\
\hline \multirow[t]{3}{*}{ Age } & Below 40 years & 1 & Residence & Rural & 1 \\
\hline & 41 to 60 years & 2 & & Urban & 2 \\
\hline & $60+$ years & 3 & Duration of diabetes & More than 5 years & 1 \\
\hline \multirow[t]{2}{*}{ Sex } & Male & 1 & & Less than 5 years & 2 \\
\hline & Female & 2 & Complications of diabetes & Yes & 1 \\
\hline \multirow[t]{2}{*}{ Religion } & Muslim & 1 & & No & 2 \\
\hline & Hindu & 2 & Type of medication & Oral hypoglycemic drug & 1 \\
\hline \multirow[t]{3}{*}{ Marital status } & Married & 1 & & Insulin & 2 \\
\hline & Single & 2 & & Mixed & 3 \\
\hline & Widowed/Divorced & 3 & Frequency of health care center visit & Irregular & 1 \\
\hline \multirow[t]{4}{*}{ Education level } & Uneducated & 1 & & Regular & 2 \\
\hline & Primary & 2 & Family history of diabetes & Yes & 1 \\
\hline & Secondary & 3 & & No & 2 \\
\hline & Higher study & 4 & & & \\
\hline \multirow{3}{*}{$\begin{array}{l}\text { Family status (measured by } \\
\text { monthly family income (in taka)) }\end{array}$} & Low (<BDT15000) & 1 & & & \\
\hline & Middle (BDT15000-30000) & 2 & & & \\
\hline & Higher (>BDT30000) & 3 & & & \\
\hline
\end{tabular}




\section{Results}

\section{Socio-demographic characteristics}

A total of 244 diabetes patients were enrolled in this study. The socio-demographic characteristics and diabetes-related factors are presented in Table 2. The participants were predominantly female with a mean age (SD) of 54.15 (13.18) years. Their mean (SD) duration of diabetes was 8.89 (5.42) years and two-third of them had uncontrolled diabetes. More than $60 \%$ of the participants were suffering from diabetes-related complications (Table 2).

\section{Rate of CAM using patients}

It was observed that more than $35 \%$ of diabetes patients used CAM for controlling their diabetes. The sex distribution of CAM users was similar, and older patients used CAM more frequently than younger ones. Patients came from rural areas, and living in low-income families used CAM more than their counterparts. Patients diagnosed as diabetic for more than five years, having a family history of diabetes, suffering from diabetes-related complications, and doing irregular follow-up were found to have a higher rate of CAM use. Chi-square test demonstrated that patients' age group, education level, family income, residence, duration of diabetes, complication of diabetes, frequency of health care visit, and family history of diabetes were the significantly associated factors of CAM usage (Table 2).

Only significantly associated factors provided by the Chi-square test were considered as independent variables in the multivariate logistic regression model. After controlling the effect of other factors, this model demonstrated that uneducated diabetes patients were more likely to use CAM than higher educated patients $[\mathrm{AOR}=$ 3.40; 95\% CI: $1.170-9.877, p<0.05]$. It was noted that patients who lived in low and middle-income families had 8.703 times higher risk for using CAM than higherincome family patients respectively [AOR $=8.703 ; 95 \%$ CI: $2.151-35.216, p<0.01]$ and $2.041[\mathrm{AOR}=2.041 ; 95 \%$ CI: $0.998-4.174, \mathrm{p}<0.05]$. Patients suffering from diabetes for more than 5 years were more likely to use CAM than their counterparts $[A O R=2.821 ; 95 \% \mathrm{CI}$ : 1.338-5.947, $\mathrm{p}<0.01$ ]. Rural patients had shown more chance of using CAM than urban patients $[A O R=1.767$; 95\% CI: 0.903-3.461, $p=0.097$ ], and patients who had a family history of diabetes were more likely to use CAM than those who did not have a family history [AOR 1.698; 95\% CI: 0.937-3.077, $p<0.081$ ] (Table 3).

\section{CAM-related characteristics among CAM users}

The highest number of CAM users (67.4\%) used herbal products (such as Gynura procumbens, locally known as 'diabetes tree', fenugreek, bitter gourd, etc.), followed by homeopathic medicine (37.2\%) and traditional/ religious methods (9.3\%) (Table 4).

Most of the CAM users (72\%) reported that they got information about CAM from their friends, neighbors, and family members, while others reported CAM practitioners (such as 'kabiraj' or traditional healers, herbal or homeopathic medicine practitioners) and mass media or advertisement of CAM products (Table 4).

Table 4 also describes the characteristics of using CAM among study participants. Almost 28\% of CAM users reported that they used CAM as an alternative to mainstream medicine while others reported that they used CAM on a complementary basis. CAM users believed that CAM would help in better diabetes control and easy availability and lower cost were the most commonly cited reasons for using CAM (44.2 and 27.9\% respectively) followed by dissatisfaction with conventional medicine $(9.3 \%)$ and fewer side effects (7\%). More than $23 \%$ of users used CAM without any specific reason. Almost half of the users reported the efficacy of CAM as 'nothing significant', while others reported as somewhat good, $14 \%$ of CAM users experienced side-effects. Gastrointestinal upset, vertigo, and hypoglycemia were commonly reported side-effects of CAM (Table 4).

\section{Effect of using CAM on glycemic control}

Almost $76 \%$ of CAM users had poor glycemic control, while the rate was $61.4 \%$ among CAM non-users. It was found that a greater number of non-CAM users (38.6\%) could control their diabetes better than CAM-users (24\%). The simple logistic regression model showed that non-CAM users had 1.946 times better control of their diabetes than CAM users. When we controlled the effect of socio-economic, demographic, and diabetes-related factors, it was observed that non-CAM users were more likely to control their diabetes than CAM user patients [AOR $=2.255 ; 95 \% \quad \mathrm{CI}: 1.147-4.437, p$-value $<0.05]$ (Table 5).

\section{Discussion}

The present study provided insight into the prevalence and sociodemographic and diabetes-related factors of using CAM among T2DM patients of the northern part of Bangladesh as well as the patients' attitude towards using these. The overall prevalence of using CAM found in our study was $35.2 \%$. Being a localized study in a hospital serving patients mainly from the northern part of Bangladesh (Rajshahi, Rangpur, and part of Khulna division), findings of this study may not be inferential for all the patients of different regional and cultural background. Despite the fact, it was the first report on the prevalence of using CAM among Bangladeshi diabetic patients according to our knowledge. However, the rate was much lower than the estimated rate of CAM use 
Table 2 Socio-demographic and disease-related characteristics of the study sample $(n=244)$ and their association with CAM use

\begin{tabular}{|c|c|c|c|c|}
\hline Characteristics & Total $(n=244)$ & CAM users $(n=86)$ & CAM non-users $(n=158)$ & $p$-value \\
\hline \multicolumn{5}{|l|}{ Socio-demographic factors } \\
\hline \multicolumn{5}{|l|}{ Age } \\
\hline Below 40 years & $31(12.7)$ & $5(16.1)$ & $26(83.9)$ & \multirow[t]{3}{*}{0.005} \\
\hline 41 to 60 years & $140(57.4)$ & $46(32.9)$ & $94(67.1)$ & \\
\hline $60+$ years & $73(29.9)$ & $35(47.9)$ & $38(52.1)$ & \\
\hline \multicolumn{5}{|l|}{ Sex } \\
\hline Male & $100(41.0)$ & $38(38.0)$ & $62(62.0)$ & \multirow[t]{2}{*}{0.453} \\
\hline Female & $144(59.0)$ & $48(33.3)$ & $96(66.7)$ & \\
\hline \multicolumn{5}{|l|}{ Religion } \\
\hline Muslim & $192(78.7)$ & $72(37.5)$ & $120(62.5)$ & \multirow[t]{2}{*}{0.157} \\
\hline Hindu & $52(21.3)$ & $14(26.9)$ & $38(73.1)$ & \\
\hline \multicolumn{5}{|l|}{ Marital status } \\
\hline Married & $184(75.4)$ & $68(37.0)$ & $116(63.0)$ & \multirow[t]{3}{*}{0.549} \\
\hline Single & $16(6.6)$ & $4(25.0)$ & $12(75.0)$ & \\
\hline Widowed/Divorced & $44(18.0)$ & $14(31.8)$ & $30(68.2)$ & \\
\hline \multicolumn{5}{|l|}{ Education level } \\
\hline None & $22(9.0)$ & $12(54.5)$ & $10(45.5)$ & \multirow[t]{4}{*}{0.042} \\
\hline Primary & $68(27.9)$ & $28(41.2)$ & $40(58.8)$ & \\
\hline Secondary & $108(44.3)$ & $34(31.5)$ & $74(68.5)$ & \\
\hline Higher study & $46(18.9)$ & $12(26.1)$ & $34(73.9)$ & \\
\hline \multicolumn{5}{|l|}{ Family income } \\
\hline Low & $16(6.6)$ & $12(75.0)$ & $4(25.0)$ & \multirow[t]{3}{*}{0.001} \\
\hline Middle & $130(53.3)$ & $54(41.5)$ & $76(58.5)$ & \\
\hline Higher & $98(40.2)$ & $20(20.4)$ & 78 (79.6) & \\
\hline \multicolumn{5}{|l|}{ Residence } \\
\hline Rural & $108(44.3)$ & $52(48.1)$ & $56(51.9)$ & \multirow[t]{2}{*}{0.001} \\
\hline Urban & $136(55.7)$ & $34(25.0)$ & $102(75.0)$ & \\
\hline \multicolumn{5}{|l|}{ Diabetes related factors } \\
\hline \multicolumn{5}{|l|}{ Duration of diabetes } \\
\hline More than 5 years & $84(34.4)$ & $68(42.5)$ & $92(57.5)$ & \multirow[t]{2}{*}{0.001} \\
\hline Less than 5 years & $160(65.6)$ & $18(21.4)$ & $66(78.6)$ & \\
\hline \multicolumn{5}{|l|}{ Complications of diabetes } \\
\hline Yes & $148(60.7)$ & $62(41.9)$ & $86(58.1)$ & \multirow[t]{2}{*}{0.007} \\
\hline No & $96(39.3)$ & $24(25.0)$ & $72(75.0)$ & \\
\hline \multicolumn{5}{|l|}{ Type of medication } \\
\hline Oral hypoglycemic drug & $121(49.6)$ & $41(47.6)$ & $80(50.7)$ & \multirow[t]{3}{*}{0.903} \\
\hline Insulin & $69(28.3)$ & $25(29.1)$ & $44(27.8)$ & \\
\hline Mixed & $54(22.1)$ & $20(23.3)$ & $34(21.5)$ & \\
\hline \multicolumn{5}{|c|}{ Frequency of health care center visit } \\
\hline Irregular & $110(45.1)$ & $56(41.8)$ & 78 (58.2) & \\
\hline Regular & $134(54.9)$ & $30(27.3)$ & $80(72.7)$ & 0.018 \\
\hline \multicolumn{5}{|l|}{ Family history of diabetes } \\
\hline Yes & $108(44.3)$ & $48(44.4)$ & 60 (55.6) & 0.007 \\
\hline No & $136(55.7)$ & $38(27.9)$ & $98(72.1)$ & \\
\hline
\end{tabular}


Table 3 Correlates of CAM use in multivariate logistic regression among the study sample

\begin{tabular}{|c|c|c|c|}
\hline & AOR & 95\% Cl for AOR: Lower-Upper & $p$-value \\
\hline \multicolumn{4}{|l|}{ Age } \\
\hline Below 40 years & 0.543 & $0.164-1.799$ & 0.317 \\
\hline 40 to 60 years & 0.650 & $0.339-1.245$ & 0.194 \\
\hline $60+$ years & 1 & & \\
\hline \multicolumn{4}{|l|}{ Education level } \\
\hline None & 3.400 & $1.170-9.877$ & 0.025 \\
\hline Primary & 1.983 & $0.877-4.487$ & 0.100 \\
\hline Secondary & 1.302 & $0.601-2.821$ & 0.504 \\
\hline Higher study & 1 & & \\
\hline \multicolumn{4}{|l|}{ Family income } \\
\hline Low & 8.703 & $2.151-35.216$ & 0.002 \\
\hline Middle & 2.041 & $0.998-4.174$ & 0.045 \\
\hline Higher & 1 & & \\
\hline \multicolumn{4}{|l|}{ Residence } \\
\hline Rural & 1.767 & $0.903-3.461$ & 0.097 \\
\hline Urban & 1 & & \\
\hline \multicolumn{4}{|l|}{ Duration of diabetes } \\
\hline More than 5 years & 2.821 & $1.338-5.947$ & 0.006 \\
\hline Less than 5 years & 1 & & \\
\hline \multicolumn{4}{|c|}{ Complications of diabetes } \\
\hline Yes & 1.189 & $0.613-2.307$ & 0.609 \\
\hline No & 1 & & \\
\hline \multicolumn{4}{|l|}{ Health care center visit } \\
\hline Irregular & 1.210 & $0.651-2.249$ & 0.547 \\
\hline Regular & 1 & & \\
\hline \multicolumn{4}{|c|}{ Family history of diabetes } \\
\hline Yes & 1.698 & $0.937-3.077$ & 0.081 \\
\hline No & 1 & & \\
\hline
\end{tabular}

among the general population of the country, which was 70 to $75 \%$ in a previous study [14]. The finding was also lower compared to the different countries of Asia and North America. For example, prevalence of using CAM among diabetic patients in neighboring India was $67.7 \%$ [17], in Malaysia 62.5\% [8], in Taiwan 61\% [18], in Korea 65\% [19], in Thailand 47\% [20] and in Turkey 41\% [21]. Among American countries, in the USA the prevalence was 57\% [22] and in Mexico, it was 62\% [23]. The prevalence of using CAM among our study populations was higher compared to the UK (17\%) [24] and Australia (23.6\%) [25]. Different socio-cultural orientations, patients' health beliefs, and attitudes, as well as the health care system and access to modern medicine, could be attributable to the regional variation of using CAM. Moreover, variations in defining CAM in different study designs might have also contributed to this variation.
Table 4 CAM related characteristics among CAM users $(n=86)$

\begin{tabular}{|c|c|c|}
\hline CAM related characteristics & Number & Percent \\
\hline \multicolumn{3}{|l|}{ Type of used CAM } \\
\hline Herbal products & 58 & 67.4 \\
\hline Leaf of Gynura procumbens & 42 & 48.8 \\
\hline Fenugreek & 23 & 26.7 \\
\hline Bitter gourd & 17 & 19.8 \\
\hline Turmeric & 14 & 16.3 \\
\hline Okra & 26 & 30.2 \\
\hline Others & 9 & 10.5 \\
\hline Homeopathic medicine & 32 & 37.2 \\
\hline Traditional/religious method & 8 & 9.3 \\
\hline $\begin{array}{l}\text { Multivitamin/food supplements (other than } \\
\text { prescription) }\end{array}$ & 5 & 5.8 \\
\hline Others & 3 & 3.5 \\
\hline \multicolumn{3}{|l|}{ Source of information about CAM } \\
\hline Friends/ neighbors & 44 & 51.2 \\
\hline Family members & 18 & 20.9 \\
\hline Media/ advertisements & 10 & 11.6 \\
\hline $\begin{array}{l}\text { CAM practitioners (Kabiraj/Herbal/ Homeo } \\
\text { practitioner) }\end{array}$ & 12 & 13.9 \\
\hline Diabetes doctor & 2 & 2.3 \\
\hline \multicolumn{3}{|l|}{ Mode of CAM use } \\
\hline As alternative therapy & 24 & 27.9 \\
\hline As complementary therapy & 62 & 72.1 \\
\hline \multicolumn{3}{|l|}{ Reasons of CAM use } \\
\hline CAM helps in diabetes control & 38 & 44.2 \\
\hline Easily available and cheap & 24 & 27.9 \\
\hline Dissatisfied with Conventional medicine & 8 & 9.3 \\
\hline Less side effects & 6 & 7 \\
\hline No specific cause & 20 & 23.3 \\
\hline \multicolumn{3}{|l|}{ Self-reported efficacy of CAM } \\
\hline Very good & 12 & 14 \\
\hline Good & 28 & 32.6 \\
\hline Nothing significant & 46 & 53.5 \\
\hline \multicolumn{3}{|l|}{ Experienced any side effect } \\
\hline No & 74 & 86 \\
\hline Yes & 12 & 14 \\
\hline \multicolumn{3}{|l|}{ Reported side effects $(n=12)$} \\
\hline Abdominal discomfort & 6 & 50 \\
\hline Nausea, vomiting & 4 & 33.3 \\
\hline Vertigo & 2 & 16.6 \\
\hline Hypoglycemia & 2 & 16.6 \\
\hline Others & 3 & 36 \\
\hline
\end{tabular}


Table 5 Effect of using CAM on glycemic control among study sample $(n=244)$

\begin{tabular}{lllllll}
\hline Glycemic control & Poor & Good & COR $(95 \% \mathrm{Cl})$ & p-value & AOR $^{\text {a }}(95 \% \mathrm{Cl})$ & $p$-value \\
\hline CAM non-users & $97(61.4)$ & $61(38.6)$ & $1.946(1.082-3.501)$ & 0.033 & $2.255(1.147-4.437)$ \\
CAM users & $65(75.6)$ & $21(24.4)$ & 1 & & 1
\end{tabular}

adjusted for socio-demographic factors, duration of diabetes and frequency of health care center visit

Patients from lower-income families, without education and suffering from diabetes for a longer time, were more likely to use CAM. Longer duration of disease was also reported as a predictor of using CAM in the USA and India along with older age and higher educational attainment and higher family income [17, 26], though our finding was opposite in case of educational and socioeconomic status. Different studies from Asian countries did not find a significant association of using CAM with socio-demographic or disease-related characteristics $[7,8]$.

Herbal products were reported as the most commonly used CAM followed by homeopathic medicine. Herbal products were also reported as the most popular alternative therapy in different Asian countries [7, 8, 17]. The rich floral diversity of this region has constituted indigenous herbal medicine as an important component of the primary healthcare system of Bangladesh [27]. Homeopathic medicine is also frequently used in this county. Lower cost and patients' positive perception about this therapy as effective for long term cure and fewer side effects have made this treatment widely acceptable [28]. However, traditional and religious methods, acupuncture, energy therapies like reiki, and mind-body interventions like yoga or tai-chi were less commonly practiced in this country compared to other Asian countries like Malaysia and Taiwan [8, 18]. Family and friends were the most frequently reported sources of information about CAM, which was consistent with the findings of other Asian countries [7, 18]. Most of the patients attending the present study used these alternative therapies as complementary to conventional treatment. A similar finding was reported in a study from Lebanon [7]. This is an important concern for the physicians to look for whether the patients are using other alternative therapy, as it can be a potential source of drug interaction [11] as well as patients' non-compliance to the therapy and ultimately hamper the optimum glycemic management.

Positive attitude toward the efficacy of CAM and easy availability and low cost were commonly reported reasons for using CAM. It is very practical to look for alternative and cheap therapy in a lower-middle-income country like Bangladesh, especially among the patients of a government hospital, where most of the patients belong to lower socio-economic group, and diabetes management causes a high out-of-pocket expenditure [29,
30]. Surprisingly, only a few patients were dissatisfied with conventional treatment and more than half of the patients who were using CAM reported that these agents were not effective in diabetes control. Moreover, almost $14 \%$ of patients who were using CAM reported different types of side effects, most commonly gastrointestinal discomfort. These findings were similar to the previous reports from Malaysia [7], Thailand [8], and Lebanon [17]. Perhaps most of the users were using these products as an experiment for self-care of diabetes as reported by a study from Lebanon [7]. Another study from the USA reported similar findings and hypothesized that patients were using alternative therapies influenced by their cultural values, beliefs, and philosophical orientations toward health and life rather than being dissatisfied with conventional medicine [31]. Moreover, as conventional management of diabetes needs a disciplined lifestyle for diet, lifestyle, and behavior, which is often hard to maintain, these patients try to compensate by using CAM as they believe it can offer more personal autonomy and control over their disease [32].

According to the finding of our study, using CAM had a negative impact on glycemic control. This issue remained ambiguous as studies reported the different effects of CAM on diabetic management. Several studies conducted among diabetes patients reported that using CAM was associated with positive health behavior and better self-management of diabetes, as it may be part of a broader lifestyle $[6,11,31]$. In these studies, CAM use was associated with higher educational attainment that could be an independent predictor of good glycemic control, whereas, in our study, patients with lower educational attainment mostly used CAM. Moreover, these studies did not report any quantitative evidence on glycemic control. However, there are some evidences from different countries like Malaysia and Israel, reporting that consumers of CAM had no significant difference of HbA1c compared to non-users, though these studies compared only the mean of HbA1c, which was not adjusted for other potential variables $[8,33,34]$.

\section{Strength of the study}

The present study was one of the very first attempts to determine the rate and influencing factors of using CAM among the diabetes patients of Bangladesh. This provides important evidence on the effect of CAM on glycemic control of diabetes patients that can guide the 
clinicians for optimum diabetes management. The population included in this study represents a great portion of the overall diabetes patients of Bangladesh, so the result can be inferred for the majority of the patients.

\section{Limitation of the study}

A number of limitations of this study are worth mentioning. This study was conducted in a tertiary care government hospital of northern Bangladesh that may not reflect the original picture of the total diabetic population of the country. Another important limitation was its sample size was relatively small for robust statistical inference. The predicted prevalence of CAM usage from different evidences that was used to calculate sample size was much higher than the actual prevalence found in this study. A greater sample size would be considered for better statistical power, which was not possible for our limited resources. The prevalence and patterns of CAM use among patients who are not on regular follow-up by physicians could not be figured out. Although participants were assured of the confidentiality of their responses it could not be ascertained that patients did not experience the social desirability bias, potentially altering their answers to satisfy their health care providers. A more extensive study including different socio-cultural factors and both quantitative and qualitative method is necessary for a better understanding of the patients' perspectives of using CAM. The definition of good glycemic control used here $(\mathrm{HbA1c}<7 \%)$ was previously used and proved sensitive for the diabetic patients of Bangladesh $[15,16]$. However, the change of HbA1c might be a better index for defining glycemic control, but due to the cross sectional design of the study, follow up of the glycemic control was not possible, which is an important shortcoming of the study. Further studies should consider the follow-up of the glycemic index.

\section{Conclusions}

From the perspective of increasing interest in CAM among diabetic patients, our study provides an insight on the prevalence and pattern of using different CAM among the diabetes patients of Bangladesh as well as shows its negative impact on glycemic control. Awareness about the ineffectiveness and side-effects of irrational use of CAM should be raised among diabetic patients by educational programs and health education measures.

\section{Supplementary information}

Supplementary information accompanies this paper at https://doi.org/10. 1186/s12906-020-03021-3.

Additional file 1. Questionnaire.

\section{Abbreviations}

CAM: Complementary and alternative medicines; RMCH: Rajshahi Medical College Hospital; COR: Crude odd's ratio; AOR: Adjusted odd's ratio; $\mathrm{Cl}$ : Confidence interval

\section{Acknowledgements}

The authors gratefully acknowledge the authority of Rajshahi Medical College for giving permission for taking data from diabetes patients at outpatient Department. The authors would also like to express their sincere gratitude to all study participants and the staff engaged in the study. The authors also like to thank Dr. Abdul Wadood, Deputy Chief Medical Officer, University of Rajshahi, Rajshahi- 6205, Bangladesh for revising throughout this manuscript.

\section{Authors' contributions}

Conceptualization: MAR, MAJR. Formal analysis: MAR, MGH. Investigation: MAR, DTA,MB, NR, KAM, Methodology: MAR, MAJR. Resources: MAR. Supervision: MAJR, MGH. Writing - original draft: MAR, DTA, MGH. Writing review \& editing: MAR, DTA, MB, NR, KAM, MAJR, MGH. All authors have read and approved the manuscript.

Funding

The authors have no support or funding to report.

\section{Availability of data and materials}

Patient-level data will be available on request, provided that approval is given from the Ethical Review Committee of Rajshahi Medical College, Rajshahi, Bangladesh.

\section{Ethics approval and consent to participate}

Ethical approval for this study was obtained from the Ethical Review Committee of Rajshahi Medical College [Ref. RMC/ERC/2017-2019/172/185]. Before the commencement of the study, written consent was obtained from participating patients after informing the objectives of the study and their right to remain or opt-out of the study if they feel uncomfortable.

\section{Consent for publication}

Not applicable.

\section{Competing interests}

The authors declare that they have no competing interest.

\section{Author details}

${ }^{1}$ Rajshahi Medical College, 6000, Rajshahi, Bangladesh. ${ }^{2}$ Jashore Medical College, Jashore 7400, Bangladesh. ${ }^{3}$ Kushtia Medical College, Kushtia 7040, Bangladesh. ${ }^{4}$ Department of Pharmacy, University of Rajshahi, -6205, Rajshahi, Bangladesh. ${ }^{5}$ Department of Statistics, University of Rajshahi, 6205, Rajshahi, Bangladesh.

Received: 18 March 2020 Accepted: 8 July 2020

Published online: 13 July 2020

\section{References}

1. Murray CJL, Lopez AD. Measuring the global burden of disease. N Engl J Med. 2013;369:448-57. https://doi.org/10.1056/NEJMra1201534.

2. IDF. IDF Diabetes Atlas 6th Edition. International Diabetes Federation, 2013. https://www.idf.org/e-library/epidemiology-research/diabetes-atlas/19-atlas-6 th-edition.html.

3. Hills AP, Arena R, Khunti K, Yajnik CS, Jayawardena R, Henry CJ, et al. Epidemiology and determinants of type 2 diabetes in South Asia. Lancet Diabetes Endocrinol. 2018;6:966-78. https://doi.org/10.1016/S22138587(18)30204-3.

4. Chang HY, Wallis M, Tiralongo E. Use of complementary and alternative medicine among people living with diabetes: literature review. J Adv Nurs. 2007:58:307-19.

5. Organization WH. Traditional medicine: growing needs and potential. 2002. https://apps.who.int/iris/bitstream/handle/10665/67294/WHO_EDM_2002.4_ ara.pdf. Accessed 15 Feb 2020.

6. Canaway R, Manderson L. Quality of life, perceptions of health and IIIness, and complementary therapy use among people with type 2 diabetes and 
cardiovascular disease. J Altern Complement Med. 2013;19:882-90. https:// doi.org/10.1089/acm.2012.0617

7. Naja F, Mousa D, Alameddine M, Shoaib H, Itani L, Mourad Y. Prevalence and correlates of complementary and alternative medicine use among diabetic patients in Beirut, Lebanon: a cross-sectional study. BMC Complement Altern Med. 2014;14:185. https://doi.org/10.1186/1472-688214-185.

8. Ching SM, Zakaria ZA, Paimin F, Jalalian M. Complementary alternative medicine use among patients with type 2 diabetes mellitus in the primary care setting: a cross-sectional study in Malaysia. BMC Complement Altern Med. 2013;13:148. https://doi.org/10.1186/1472-6882-13-148.

9. Chang H-YA, Wallis M, Tiralongo E. Predictors of complementary and alternative medicine use by people with type 2 diabetes. J Adv Nurs. 2012; 68:1256-66. https://doi.org/10.1111/j.1365-2648.2011.05827.x.

10. Barnes PM, Powell-Griner E, McFann K, Nahin RL. Complementary and alternative medicine use among adults: United States, 2002. Adv Data. 2004; (343):1-19.

11. Bell RA, Stafford JM, Arcury TA, et al. Complementary and Alternative Medicine Use and Diabetes Self-Management Among Rural Older Adults. Complement Health Pract Rev. 2006;1 (2):95-106. https://doi.org/10.1177/ 1533210106292461.

12. Marles RJ, Farnsworth NR. Antidiabetic plants and their active constituents. Phytomedicine. 1995;2:137-89.

13. Funnell MM, Anderson RM. The problem with compliance in diabetes. J Am Med Assoc. 2000;284:1709.

14. Islam M, Farah S. How complementary and alternative medicine (CAM) is promoted in Bangladesh?: a critical evaluation of the advertisements published in local newspapers; 2007.

15. Afroz A, Chowdhury HA, Shahjahan M, Hafez MA, Hassan MN, Ali L. Association of good glycemic control and cost of diabetes care: experience from a tertiary care hospital in Bangladesh. Diabetes Res Clin Pract. 2016; 120:142-8.

16. Selim S. Frequency and pattern of chronic complications of diabetes and their association with glycemic control among adults with type 2 diabetes in Bangladesh. Diabetes Metab Syndr Clin Res Rev. 2017;11:S329-32. https:// doi.org/10.1016/j.dsx.2017.03.010.

17. Kumar D, Bajaj S, Mehrotra R. Knowledge, attitude and practice of complementary and alternative medicines for diabetes. Public Health. 2006; 120:705-11.

18. Chang H-yA, et al. "Use of Complementary and Alternative Medicine among People with Type 2 Diabetes in Taiwan: A Cross-Sectional Survey." EvidenceBased Complementary and Alternative Medicine. 2011;2011:983792.

19. Lee MS, Lee MS, Lim HJ, Moon SR. Survey of the use of complementary and alternative medicine among Korean diabetes mellitus patients. Pharmacoepidemiol Drug Saf. 2004;13:167-71.

20. Ceylan S, Azal Ö, Taşlipinar A, Türker T, Açikel CH, Gulec M. Complementary and alternative medicine use among Turkish diabetes patients. Complement Ther Med. 2009;17:78-83.

21. Moolasarn S, Sripa S, Kuessirikiet V, Sutawee K, Huasary J, Chaisila C, et al. Usage of and cost of complementary/alternative medicine in diabetic patients. J Med Assoc Thail. 2005;88:1630-7 http://www.ncbi.nlm.nih.gov/ pubmed/16471112. Accessed 15 Feb 2020

22. Yeh GY, Eisenberg DM, Davis RB, Phillips RS. Use of complementary and alternative medicine among persons with diabetes mellitus: results of a national survey. Am J Public Health. 2002:92:1648-52.

23. Argáez-López N, Wacher NH, Kumate-Rodríguez J, Cruz M, Talavera J, Rivera-

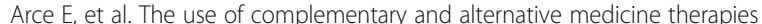
in type 2 diabetic patients in Mexico [3]. Diabetes Care. 2003;26:2470-1.

24. Leese GP, Gill GV, Houghton GM. Prevalence of complementary medicine usage within a diabetes clinic. Pract Diabetes Int. 1997;14:207-8. https://doi. org/10.1002/pdi.1960140711.

25. Clifford RM, Batty KT, Davis W, Davis TM. Prevalence and predictors of complementary medicine usage in diabetes: Fremantle diabetes study. $J$ Pharm Pract Res. 2003;33:260-4. https://doi.org/10.1002/jppr2003334260.

26. Egede LE, Ye X, Zheng D, Silverstein MD. The prevalence and pattern of complementary and alternative medicine use in individuals with diabetes. Diabetes Care. 2002;25:324-9

27. Khan NA, Rashid AZMM. A study on the indigenous medicinal plants and healing practices in Chittagong Hill tracts (Bangladesh). 2006. www africanethnomedicines.net. Accessed 16 Feb 2020.
28. Elahee SF, Rahman MM, Rahman MM, Hossain S, Zaki M. Who seek homeopathic treatment? Bangladesh Med J. 1970;37:37-40.

29. Shariful Islam SM, Lechner A, Ferrari U, Laxy M, Seissler J, Brown J, Niessen LW, Holle R. Healthcare use and expenditure for diabetes in Bangladesh. BMJ global health. 2017;2(1):e000033. https://doi.org/10.1136/bmjgh-2016000033.

30. Afroz A, Habib SH, Chowdhury HA, Paul D, Shahjahan M, Hafez MA, et al. Healthcare cost of type 2 diabetes mellitus in Bangladesh: a hospital-based study. Int J Diabetes Dev Ctries. 2016;36:235-41.

31. Astin JA. Why patients use alternative medicine: results of a national study. J Am Med Assoc. 1998:279:1548-53.

32. Chatzimarkakis J. Why patients should be more empowered: a European perspective on lessons learned in the management of diabetes. J Diabetes Sci Technol. 2010;4:1570-3.

33. Hasan SS, Loon WC, Ahmadi K, Ahmed SI, Bukhari NI. Reasons, perceived efficacy and factors associated with complementary and alternative medicine use among Malaysian patients with diabetes mellitus. $\mathrm{Br} J$ Diabetes Vasc Dis. 2011;11:92-8. https://doi.org/10.1177/1474651410398367.

34. Koren R, Lerner A, Tirosh A, Zaidenstein R, Ziv-Baran T, Golik A, et al. The use of complementary and alternative medicine in hospitalized patients with type 2 diabetes mellitus in Israel. J Altern Complement Med. 2015;21:395-400.

\section{Publisher's Note}

Springer Nature remains neutral with regard to jurisdictional claims in published maps and institutional affiliations.
Ready to submit your research? Choose BMC and benefit from:

- fast, convenient online submission

- thorough peer review by experienced researchers in your field

- rapid publication on acceptance

- support for research data, including large and complex data types

- gold Open Access which fosters wider collaboration and increased citations

- maximum visibility for your research: over $100 \mathrm{M}$ website views per year

At $\mathrm{BMC}$, research is always in progress.

Learn more biomedcentral.com/submissions 